\title{
Paravertebral And Epidural Blocks For Post Thoracotomy Pain
}

\author{
Fatma A. A. Zorob, Amira M. Nassar, And Tarek El-Said \\ Anesthesia department, Faculty of Medicine for Girls, \\ Al-Azhar University.
}

\begin{abstract}
:
Thoracic anesthesia offers particular challenge. Thoracic patients frequently have a painful wound after surgery. So analgesia after thoracic surgery is of particular significance. In the present study we assessed the efficacy of thoracic paravertebral and epidural blockade on post thoracotomy pain and pulmonary function. Thirty adult ASA I-III patients undergoing elective thoracic surgery were enrolled in this study. they were randomly divided into two groups : paravertebral and epidural group (15 patients each). Both percutaneous paravertebral and epidural catheters were placed preoperatively. Before chest closure each patient received a bolus dose of bupivacaine $(0.25 \%)$ according to its height. This was followed by postoperative bupivacaine infusion $(0.25$ $\%) 0.1 \mathrm{ml} \mathrm{kg}^{-1} \mathrm{~h}^{-1}$ in both groups. Also patients were encouraged to take supplementary doses of morphine from a patient controlled analgesia (PCA). Subjective pain relief was assessed on a linear visual analogue scale and pulmonary function was measured by spirometry. Stress responses to noxious stimuli was assessed by plasma levels of cortisol and glucose. Respiratory variables were recorded throughout the study period. Also sensory level of analgesia and performance status were assessed in the two groups. Although we found significantly lower visual analogue pain scores at rest and on maximal coughing in the paravertebral compared to the epidural group, no significant difference in patient controlled morphine requirements was noted between the two groups. Pulmonary function (FVC, $\mathrm{FEV}_{1}$ and PEFR) was significantly better in the paravertebral group. Meanwhile no significant difference in respiratory variables was recorded between the two groups. Paravertebral block produced significantly diminished stress responses to noxious stimuli as manifested by less increase in plasma cortisol level than in epidural block. Sensory levels of analgesia and performance status was similar in both groups. Side effects as hypotension, urine retention, nausea and difficulty in breathing were troublesome in the epidural group. While nausea and difficulty in breathing were less in paravertebral group. Conclusion : Like epidural analgesia, paravertebral block deserves to be considered for post thoracotomy pain relief.
\end{abstract}

\section{Introduction :}

Thoracotomy with its associated pathophysiological abnormalities prod uce one of the most damage insult which it is possible to inflict on patients. Severe chest wall trauma, damaged peripheral nerves and central

nervous system hypersensitivity are implicated as the main causes of post thoracotomy pain (Sabanathan et al., 1993). Relief of this pain is beneficial to patient providing comfort, facilitating physi -otherapy and effective 


\section{Paravertebral And Epidural}

expectoration. Many strategies have been described to control this pain; systemic opioids, non steroidal antiinflammatory drugs and regional analgesia. Among these regional anesthesia was considered most effective and logical approach (Richardson et al., 1993 ; Dickenson, 1995).

Thoracic epidural anesthesia presents a technically greater challenge. The spinous processes particularly $\mathrm{T} 4$ 10 are longer and more steeply angled so that midline approach is so difficult.

The dural sac lies closer to ligamentum flavum and the spinal cord is in closer proximity to the dura. So a dural punc ture carries the risk of direct spinal cord damage (Mulroy, 1996).

Despite clinical studies showing the clinical safety of paravertebral block there appear some reservations to its use (Lönnquist, 1992). Some investigators suggest that the technique is hazardous, blind advancement of the needle may unintentionally puncture the closely underlying pleura (Mulroy, 1996). While other investigators speculated that paravertebral spread rarely exceeds two dermatomes with evidence of symp -athetic blockade being seen in fewer than $5 \%$ of patients (Cheema et al., 1995).

The aim of the present study is to compare the use of the paravertebral and epidural blocks for post thoracotomy pain relief.

\section{Methods :}

The study was done on 30 adult patients ASA I-III undergoing elective thoracic surgery in ALZAHRAA Hospital. All patients gave verbal consent for the technique. The patients were randomly divided into two groups : paravertebral and extradural group (n
$=15$ each group). Both techniques were done before start of anesthesia.

Exclusion criteria were : sepsis over the thoracic vertebrae, systemic diseases (diabetes mellitus, coagulopa thy, cardiac, hepatic or renal impairm ent), known allergy to local anesthetic and lack of patient consent.

Paravertebral group : At T6-8 ipsilateral to the thoractomy the block was performed according to the technique described by Eason and Wyatt, (1979). The patient was placed in the sitting or lateral position with the side to be blocked uppermost. After sterilization of the back of the patient, local infiltration of the skin and subcutaneous tissues with local anesthetic lidocaine $1 \%$ is performed at the point of skin puncture which is $3 \mathrm{~cm}$ from the anatomical midline. The skin is punctured with Tuohy needle $(18 \mathrm{G}$, Perifix Braun Germany) and level with the cephaloid end of the spinous process. The needle is then advanced at $90^{\circ}$ to the skin in all planes to strike the transverse process or the head of the rib at a depth of approximately $2.5-3.5$ $\mathrm{cm}$. The needle is then walked over the top of the transverse process of the rib. Loss of resistance was used as the needle passed through the costotransverse ligament. Once placement of the needle is certain an epidural catheter $(20 \mathrm{G})$ is advanced through the needle $1 \mathrm{~cm}$ beyond the needle tip.

Extradural group ; using a paramedian approach thoracic extradural catheter was introduced through a Tuohy needle. The patient was placed in the late ral or sitting position with the neck and upper back flexed as much as possible. The spinous process of the $\mathrm{T} 7$ is identified at the inferior angle of the scapula and an $\mathrm{X}$ is marked on the skin 1 to $1.5 \mathrm{~cm}$ lateral to this spinous process. After sterilization 
of the back of the patient, local infiltration of the skin and subcutaneous tissues with local anesthetic lidocaine (1 $\%)$ is performed with a thin needle and the depth of the lamina is identified. The epidural needle (Tuohy needle 18 G, Perific Braun, Germany) with a stylet is advanced onto the lamina with the bevel directed cephalad and medially at $45^{\circ}$ angle and walked of the lamina until the ligament is seated, the epidural space is identified by the loss of resistance technique. Once placement of the needle is certain an epidural catheter $(20 \mathrm{G})$ is advanced through the needle and it is passed $3-4 \mathrm{~cm}$ beyond the needle tip (Mulroy, 1996).

In both groups after advancement of the catheter, the needle is withdrawn carefully. Once out of the skin it is removed over the end of the catheter and appropriate connector is attached in a sterile manner to the free end of the catheter. After aspiration for blood or CSF a $4 \mathrm{ml}$ Lidocaine (2\%) is adminis tered as a test dose and the catheter is taped.

Pinprick test was performed in all patients before the start of anesthesia. Also the position of the catheter was examined with X-ray and contrast medium (4 $\mathrm{ml}$ of omnipaque 300 $\left.\mathrm{mg} \cdot \mathrm{ml}^{-1}\right)$.

Anesthetic technique was standardized for all patients.

Premedication morphine $0.12 \mathrm{mg} \cdot \mathrm{kg}^{-1}$ one hour before anaesthesia.

Induction : Fentanyl $2 \mu \mathrm{g} \cdot \mathrm{kg}^{-1}$, propofol $2 \mathrm{mg} \cdot \mathrm{kg}^{-1}$ and vecuronium $0.08 \mathrm{mg} . \mathrm{kg}^{-1}$ to facilitate intubation.

Maintenance : Isoflurane $1-2$ vol \% in $100 \%$ oxygen, fentanyl infusion 0.02 $\mu \mathrm{g}$. kg.min ${ }^{-1}$. Mechanical ventilation was adjusted to maintain end tidal carbon dioxide $\left(\mathrm{ETCo}_{2}\right) 32-35 \mathrm{mmHg}$.

Heart rate, electrocardiogram, invasive blood pressure and $\mathrm{ETCo}_{2}$ were monitored perioperatively using space lab monitor.

Before chest closure patients, in both groups, received a bolus dose of $0.25 \%$ bupivacaine according to the height of the patient $(8 \mathrm{ml}$ for $150-160$ $\mathrm{cm}, 10 \mathrm{ml}$ for $160-180 \mathrm{~cm}$ and $12 \mathrm{ml}$ for $>180 \mathrm{~cm})$ (Perttunen et al., 1995).

At the end of surgery neuromuscular blockade was antago nised (2.5- $5 \mathrm{mg}$ neostigmine $+1.0 \mathrm{mg}$ atropine) and endotracheal tube was removed.

On arrival in the cardiothoracic intensive care unit patients breathed 35 $\%$ oxygen via a venturi mask and a continuous infusion of bupivacaine 0.25 $\%$ was started immediately at a rate of $0.1 \mathrm{mlkg}^{-1} \mathrm{~h}^{-1}$ in the two groups (Richardson et al., 1999). The infusion was continued for 48 hours with an infusion pump (life care pump - AbottShaw).

Patients received supplementary dose of morphine from patient contro lled analgesia (PCA) device (life care pump -Abott -Shaw) which was programmed to provide a bolus dose of $30 \mu \mathrm{g} \mathrm{kg}^{-1}$, the lockout time was $7-10$ minutes until the first postoperative morning and thereafter $12-15$ minutes. Perioperative use of glucose containing IV fluid was avoided in this study.

\section{Postoperative assessment :}

1. Pain score at rest and on maximal coughing. A visual linear analogue scale (VAS) was used with patients making a mark on a $10 \mathrm{~cm}$ line $(0=$ no; $10=$ worst pain $)$.

2. Morphine requirement by PCA : at recovery from anaesthesia, then at 4, 8, 12, 24 and 48 hours postoperatively.

3. Pulmonary function tests : Before surgery (control) at 4, 8, 12, 24 , and 48 hours postoperative FVC, $\mathrm{FEV}_{1}$, and PEFR were 


\section{Paravertebral And Epidural}

measured in sitting position using spirometry (Spirosift -SP-5000).

4. Respiratory variables [respiratory rate (RR), oxygen saturation $\left(\mathrm{SaO}_{2}\right)$ and end tidal $\mathrm{CO}_{2}$ $\left(\mathrm{ETCO}_{2}\right)$ were measured at $1,4,8$, 12,24 and 48 hours postoperatively.

5. Upper and lower sensory levels of analgesia were assessed by pinprick sensation on both sides in the two groups. The most caudal and the most cranial dermatomes insensitive to the stimuli were recorded.

6. Intermittent blood samples were obtained for measurement of plasma cotrisol and blood glucose concentration before induction of anesthesia 4, 8, 12, 24 and 48 hours postoperatively.

7. Performance status (sleeping, mobility, drinking, eating and bowel function using a scale of absent (0), moderately impaired (1), slightly impaired (2) or normal (3) (Perttunen, 1995) were assessed 24 and 48 hours postoperatively.

8. Postoperative adverse effects : nausea, vomiting, hypotension, urine retention, difficulties in breathing, drowsiness, confusion, itching were recorded throughout the study.

Data were collected and analyzed using Student's t-test. Results were expressed as mean \pm Standard deviation. $\mathrm{P}<0.05$ and $\mathrm{p}<$ 0.001 were considered statistically significant. The Mann-Withney U test was used to analyze the area under the curve for plasma cortisol measurements between the two groups.

\section{Results :}

Both groups were comparable in patient's characteristics and types of surgery (table 1). In the epidural group patients experienced more pain at rest and on coughing compared to the paravertebral group throughout the study period (table 2, 3 ; figure 1, 2). Also there was no significant difference in morphine consumption between the two groups (table 4). There was an improvement in respiratory variables in both paravertebral and epidural groups. Also no significant difference in these variables were recorded between the two groups (table 5).

Segmental spread of pinprick analgesia was comparable in the two groups for up to 48 hours. The upper sensory level of analgesia was $2-3$ cranial dermatomes in both paraver tebral and epidural groups, while the lower sensory level was $4-6$ caudal dermatomes in both groups respectiv ely. Also segmental spread of pinprick was unilateral in the paravertebral group, except in three cases this was bilateral. The catheter was located correctly in all patients examined with $\mathrm{X}$-ray.

Pulmonary function tests as experienced by FVC, $\mathrm{FEV}_{1}$ and PEFR were decreased at 4 hours postopera tively compared to preoperative values in both groups. Thereafter, although improving they had not returned to preoperative values at the end of the study in both groups. There was a significant difference in pulmonary function tests between the two groups. Patients in paravertebral group showed more improvement in pulmonary function than the epidural group (table 6 , figure $3,4,5$ ).

Plasma concentrations of cortisol increased significantly from preopera tive values to 24 hours postoperatively in both paravertebral and epidural groups (table 7). Although no signi ficant difference was recorded between the two groups, when the area under the plasma concentrations versus time 
curves were compared (Mann-Whitney U test), the increases in plasma cortisol was significantly less in the paravertebral group (figure 6).

There was no significant changes in plasma glucose level throughout the study period.

There was no significant difference between the two groups in performance status on the first or second days after operation.

The incidence of adverse effects was greater in the epidural than the paravertebral group (table 6). In the epidural group 3 patients suffered from hypotension required temporary cessation of infusion and increase IV fluid infusion, 2 patients suffered from urine retention required catheterization and another 2 patients complained from numbness and heavy legs. Nausea was recorded in two patients in the paravertebral group and 4 patients in the epidural group, also difficulty in breathing was noted in 3 and 7 patients in both groups respectively.

Table (1): Patients characteristics and operation data (mean \pm SD)

\begin{tabular}{||l||l||c||}
\hline \hline & Paravertebral group & Epidural group \\
\hline Sex F/M & $6 / 9$ & $5 / 10$ \\
Age (yr) & $49.5 \pm 5.6$ & $50 \pm 7.8$ \\
Weight (kg) & $71.2 \pm 6.4$ & $70.3 \pm 8.5$ \\
Height (cm) & $165.4 \pm 5.6$ & $169.2 \pm 8.4$ \\
Surgery & & \\
$\quad 7$ & 5 \\
$\quad$ Pneumonectomy & 3 & 6 \\
$\quad$ Lobectomy & $115.33 \pm 32.09$ & 5 \\
$\quad$ Exploration & $147 \pm 32.89$ & $107.93 \pm 32.22$ \\
Duration of operation (min) & & $138.13 \pm 37.53$ \\
Duration of anaesthesia (min) & & \\
\hline
\end{tabular}

Table (2) : Pain scores $(\mathrm{cm})$ (mean $\pm \mathrm{SD})$ at rest in both groups.

\begin{tabular}{|l||l|l||}
\hline \hline Time $(\mathrm{h})$ & Paravertebral group & Epidural group \\
\hline \hline 1 & $2.1 \pm 1.3$ & $2.6 \pm 1.4$ \\
4 & $1.3 \pm 2.6^{*}$ & $1.8 \pm 0.8^{* \# \#}$ \\
8 & $0.5 \pm 0.3^{*}$ & $1.2 \pm 0.6^{* * \#}$ \\
12 & $0.9 \pm 0.4^{* *}$ & $1.6 \pm 0.6^{* * \# \#}$ \\
24 & $0.8 \pm 0.5^{* *}$ & $1.5 \pm 0.6^{* * \# \#}$ \\
48 & $1.4 \pm 0.2^{*}$ & $1.9 \pm 0.4^{* \# \#}$ \\
\hline
\end{tabular}

$* \mathrm{p}<0.05, * * \mathrm{p}<0.01$ in comparison to first postoperative hour $\# \mathrm{p}<0.05, \# \# \mathrm{p}<0.01$ in comparison to paravertebral group 


\section{Paravertebral And Epidural}

Fig.(1): Pain scores (cm) mean $+\mathrm{SD}$ at rest in paravertebral and epidural grou

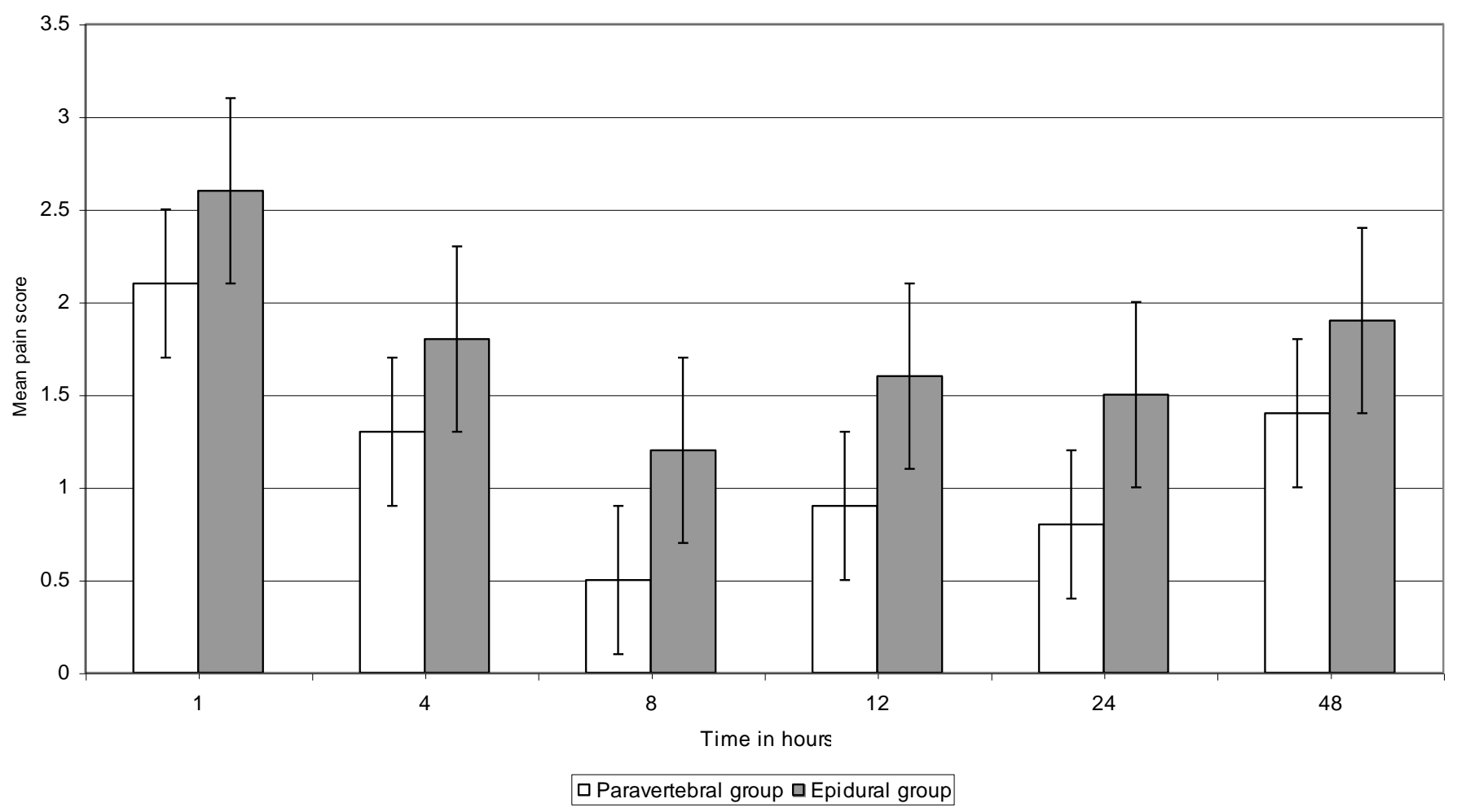

Table (3) : Pain scores $(\mathrm{cm})$ (mean $\pm \mathrm{SD}$ ) on coughing in both groups.

\begin{tabular}{|c|c|c|}
\hline Time $(\mathrm{h})$ & Paravertebral group & Epidural group \\
\hline 1 & $3.1 \pm 1.4$ & $4.2 \pm 1.3^{* \#}$ \\
\hline 4 & $2.4 \pm 0.2 *$ & $3.5 \pm 0.7$ *\# \\
\hline 8 & $1.8 \pm 0.7 * *$ & $2.6 \pm 0.8 * * \# \#$ \\
\hline 12 & $2.1 \pm 1^{*}$ & $3.2 \pm 0.1 * * \# \#$ \\
\hline 24 & $2 \pm 0.6^{*}$ & $2.9 \pm 0.8^{* * \# \#}$ \\
\hline 48 & $2 \pm 0.9 *$ & $2.6 \pm 0.4 * \#$ \\
\hline
\end{tabular}

$* \mathrm{p}<0.05, * * \mathrm{p}<0.05$ in comparison to first postoperative hour

$\# \mathrm{p}<0.05, \# \# \mathrm{p}<0.01$ in comparison to paravertebral group 
Fatma A. A. Zorob; et al .

Figure ( 2) : Pain scores (cm) (mean $+\mathrm{SD})$ on coughing in paravertebral and epidural groups

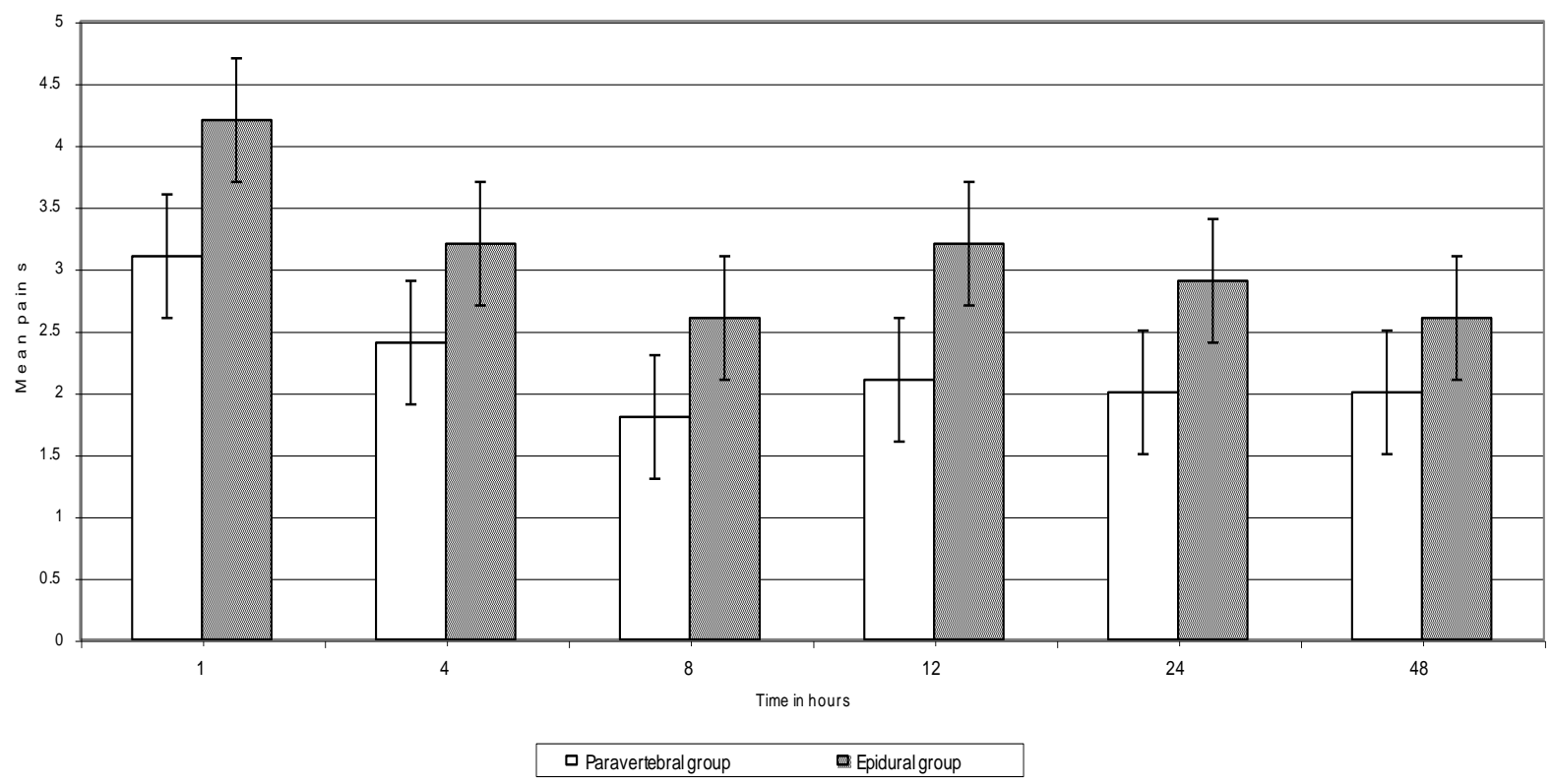

Table (4) : Morphine consumption (mg) (mean \pm SD) in paravertebral and epidural groups.

\begin{tabular}{||l||l||l||}
\hline \hline Time $(\mathrm{h})$ & Paravertebral group & Epidural group \\
\hline \hline 4 & $5.5 \pm 2.3$ & $6.2 \pm 4.7$ \\
8 & $8 \pm 6.1$ & $10.0 \pm 5.9$ \\
12 & $4.5 \pm 4.3$ & $3 \pm 3.9$ \\
24 & $4.1 \pm 3.3$ & $4.7 \pm 3.2$ \\
48 & $4 \pm 2.9$ & $4.5 \pm 3.8$ \\
\hline
\end{tabular}

Table (5) : Respiratory variables in paravertebral and extradural groups.

\begin{tabular}{|c|c|c|c|c|c|c|}
\hline Variable & 1 hour & 4 hours & 8 hours & 12 hours & 24 hours & 48 hours \\
\hline RR (breath/min) & & & & & & \\
\hline $\begin{array}{l}\text { Paravertebral } \\
\text { group }\end{array}$ & $20.87 \pm 4.07$ & $18.4 \pm 2.59^{*}$ & $17.13 \pm 2.53^{*}$ & $15.47 \pm 2.26^{* * *}$ & $14.13 \pm 1.89 * *$ & $13.53 \pm 1.55^{* * *}$ \\
\hline Extradural group & $18.0 \pm 4.19$ & $16.47 \pm 3.38 *$ & $14.4 \pm 1.96^{*}$ & $13.67 \pm 1.95^{* * *}$ & $12.67 \pm 1.63 * *$ & $11.93 \pm 0.7^{* *}$ \\
\hline $\begin{array}{l}\mathbf{E T C o}_{2}(\mathbf{m m H g}) \\
\text { Paravertebral } \\
\text { group }\end{array}$ & 4.78 & $3.09 *$ & $3 \pm 2.61 *$ & $9 *$ & $3 \pm 2.15^{*}$ & $41.87 \pm 2.48^{*}$ \\
\hline Extradural group & $37.33 \pm 5.7$ & $39.47 \pm 4.03 *$ & $40.33 \pm 2.69^{*}$ & $41.27 \pm 1.91 *$ & $41.27 \pm 1.88^{*}$ & $41.2 \pm 1.82^{*}$ \\
\hline $\begin{array}{l}\mathrm{SaO} \% \\
\text { Paravertebral } \\
\text { group }\end{array}$ & $93.13 \pm 1.55$ & $\pm 1.08^{*}$ & $96.8 \pm 1.69^{*}$ & $97.4 \pm 1.45^{*}$ & $98.47 \pm 0.83 * *$ & $98.93 \pm 1.03 * *$ \\
\hline Extradural group & $94.4 \pm 2.67$ & $95.13 \pm 1.77 *$ & $97.87 \pm 1.36^{*}$ & $97.67 \pm 1.39 *$ & $97.53 \pm 1.46^{*}$ & $98.0 \pm 1.07^{*}$ \\
\hline
\end{tabular}

$* \mathrm{p}<0.05, * * \mathrm{p}<0.01$ in comparison to first postoperative hour 


\section{Paravertebral And Epidural}

Table (6) : Pulmonary function tests expressed as percentage of predicted value (mean \pm SD) in paravertebral and epidural groups.

\begin{tabular}{|c|c|c|c|}
\hline $\begin{array}{l}\text { Pulmonary function } \\
\text { tests }\end{array}$ & Time $(\mathrm{h})$ & Paravertebral group & Epidural group \\
\hline FVC & $\begin{array}{l}\text { Preoperative } \\
\text { Postoperative } 4 \text { hrs } \\
8 \mathrm{hrs} \\
12 \mathrm{hrs} \\
24 \mathrm{hrs} \\
48 \mathrm{hrs}\end{array}$ & $\begin{array}{l}76 \pm 4.2 \\
52 \pm 6.2^{\star \star} \\
60 \pm 7.6^{\star \star} \\
65 \pm 8.0^{\star \star} \\
69 \pm 3.0^{\star} \\
74 \pm 4.1\end{array}$ & $\begin{array}{l}72 \pm 7.4 \\
44 \pm 5.7 \#^{\star \star} \\
50 \pm 6.5^{\star *} \# \# \\
52 \pm 7.4^{\star \star} \# \# \\
56 \pm 8.1^{\star \star} \# \# \\
58 \pm 9.2^{\star \star} \# \#\end{array}$ \\
\hline FEV $_{1}$ & $\begin{array}{l}\text { Preoperative } \\
\text { Postoperative } 4 \text { hrs } \\
8 \mathrm{hrs} \\
12 \mathrm{hrs} \\
24 \mathrm{hrs} \\
48 \mathrm{hrs}\end{array}$ & $\begin{array}{l}75 \pm 8.7 \\
50 \pm 8.5^{\star \star} \\
58 \pm 7.0^{\star} \\
64 \pm 8.2^{\star} \\
69 \pm 8.7 \\
72 \pm 9.2\end{array}$ & $\begin{array}{l}70 \pm 6.2 \# \\
41 \pm 6.2^{\star \star} \# \\
49 \pm 6.5^{\star \star} \# \\
52 \pm 82^{\star \star} \# \\
55 \pm 8.0^{\star \star} \# \\
58 \pm 8.5^{\star \star} \#\end{array}$ \\
\hline PEFR & $\begin{array}{l}\text { Preoperative } \\
\text { Postoperative } 4 \text { hrs } \\
8 \mathrm{hrs} \\
12 \mathrm{hrs} \\
24 \mathrm{hrs} \\
48 \mathrm{hrs}\end{array}$ & $\begin{array}{l}68 \pm 4.1 \\
54 \pm 7.9^{\star \star} \\
56 \pm 7.7^{\star \star} \\
60 \pm 8.6^{\star \star} \\
64 \pm 9.1 \\
65 \pm 7.6\end{array}$ & $\begin{array}{l}69 \pm 5.6 \\
42 \pm 5.6^{\star \star} \# \\
46 \pm 7.6^{\star \star} \# \\
54 \pm 7.8^{\star \star} \# \\
52 \pm 8.2^{\star \star} \# \\
56 \pm 4.2^{\star} \#\end{array}$ \\
\hline
\end{tabular}

$* \mathrm{p}<0.05, * * \mathrm{p}<0.01$ in comparison to preoperative value.

$\# \mathrm{p}<0.05, \# \# \mathrm{p}<0.01$ in comparison to paravertebral group

Figure (3) : Pulmonary function test (FVC) expressed as perentage of predicted value (mean + SD) in paravertebral and epidural groups

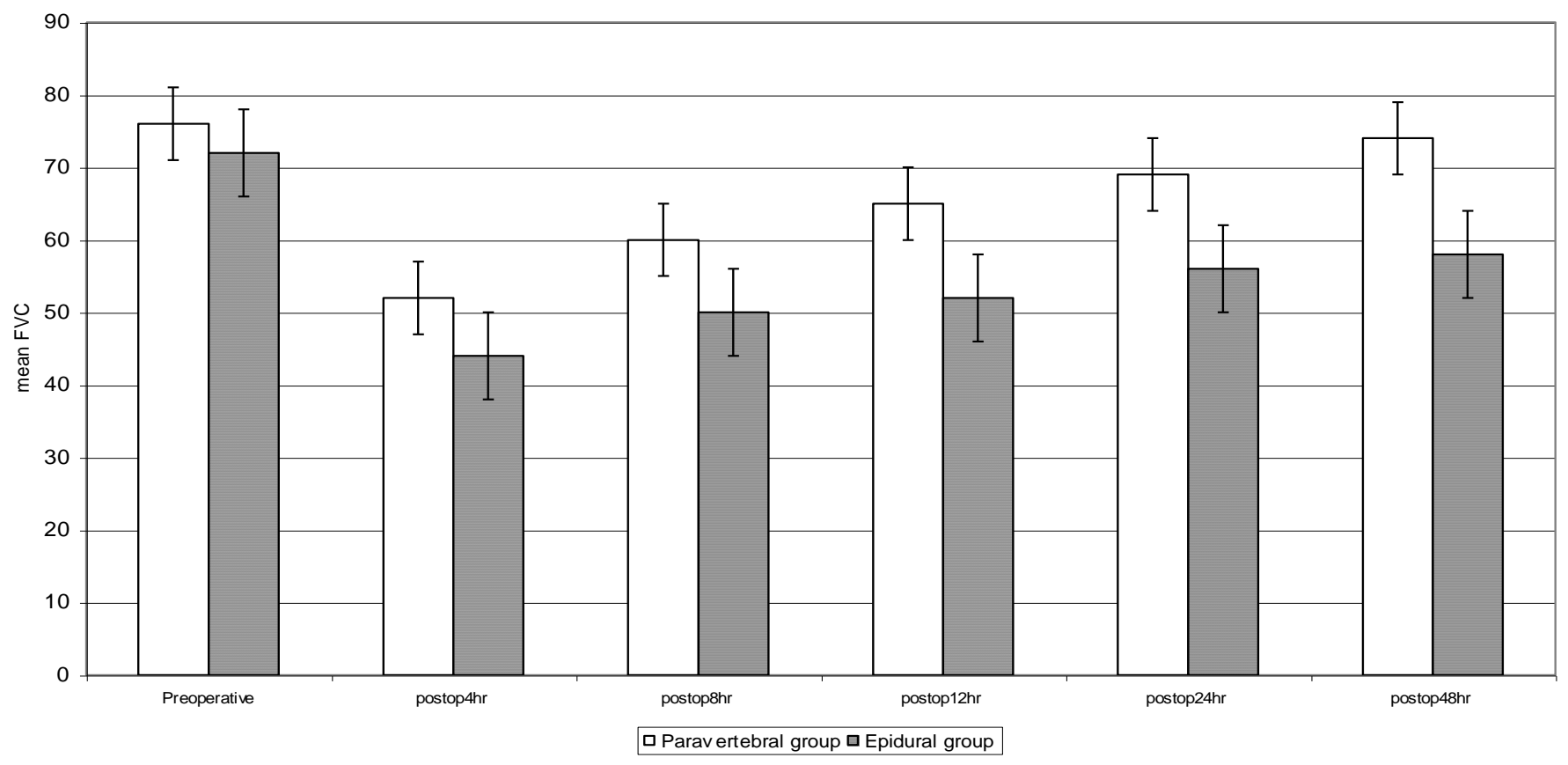


Fatma A. A. Zorob; et al .

Figure (4) : Pulmonary function test (FEV 1) expressed as percentage of predicted value (mean + SD) in paravertebral and epidural groups.

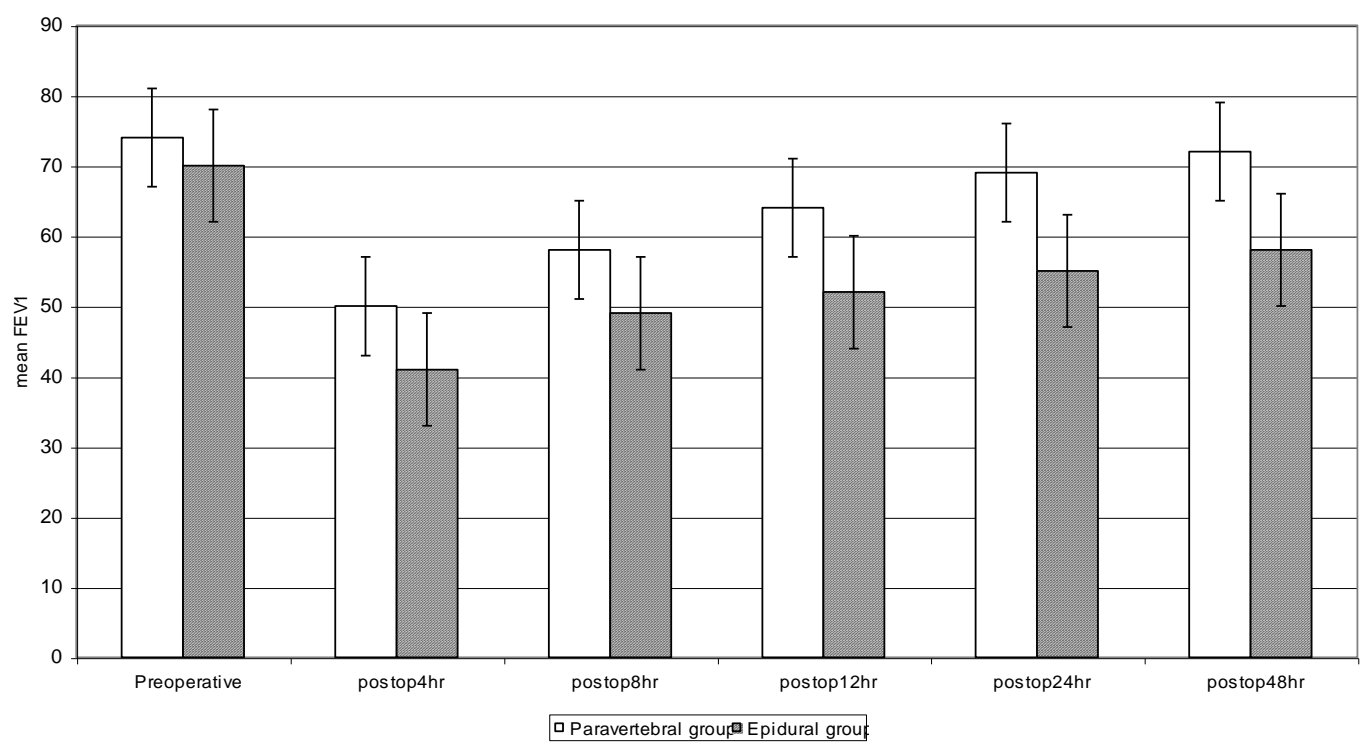

Figure (5) : Pulmonary function tests (PEFR) expressed as percentage of predicted value (mean + SD) in both groups

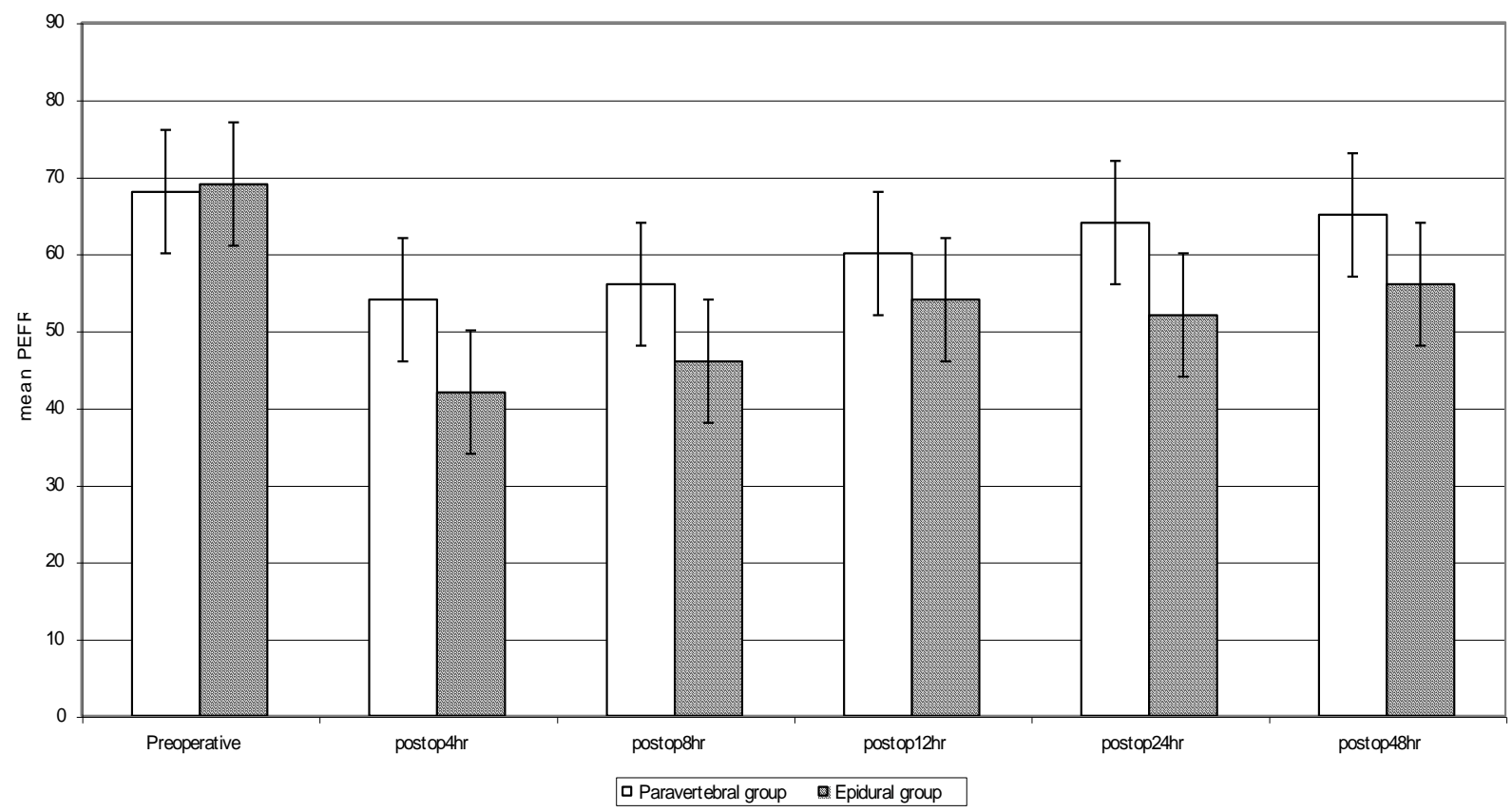




\section{Paravertebral And Epidural}

Table (7) : Plasma cortisol concentrations (mmol/liter) (mean \pm SD) in paravertebral and epidural groups.

\begin{tabular}{||l||l||l||}
\hline \hline Time $(\mathrm{h})$ & Paravertebral group & Epidural group \\
\hline \hline Before induction & $280 \pm 34$ & $285 \pm 38$ \\
1 & $360 \pm 45^{* *}$ & $380 \pm 51^{* *}$ \\
4 & $240 \pm 49^{* *}$ & $360 \pm 49 * *$ \\
8 & $320 \pm 38^{* *}$ & $340 \pm 36^{* *}$ \\
12 & $330 \pm 33^{* *}$ & $340 \pm 31^{*}$ \\
24 & $310 \pm 37^{* *}$ & $330 \pm 39^{* *}$ \\
48 & $290 \pm 28$ & $310 \pm 34$ \\
\hline
\end{tabular}

$* \mathrm{P}<0.05, * * \mathrm{p}<0.01$ in comparison to preoperative concentration.

Figure (6): Plasma cortisol concentrations (mmo/liter)(mean+SD) in paravertebral and epidural groups

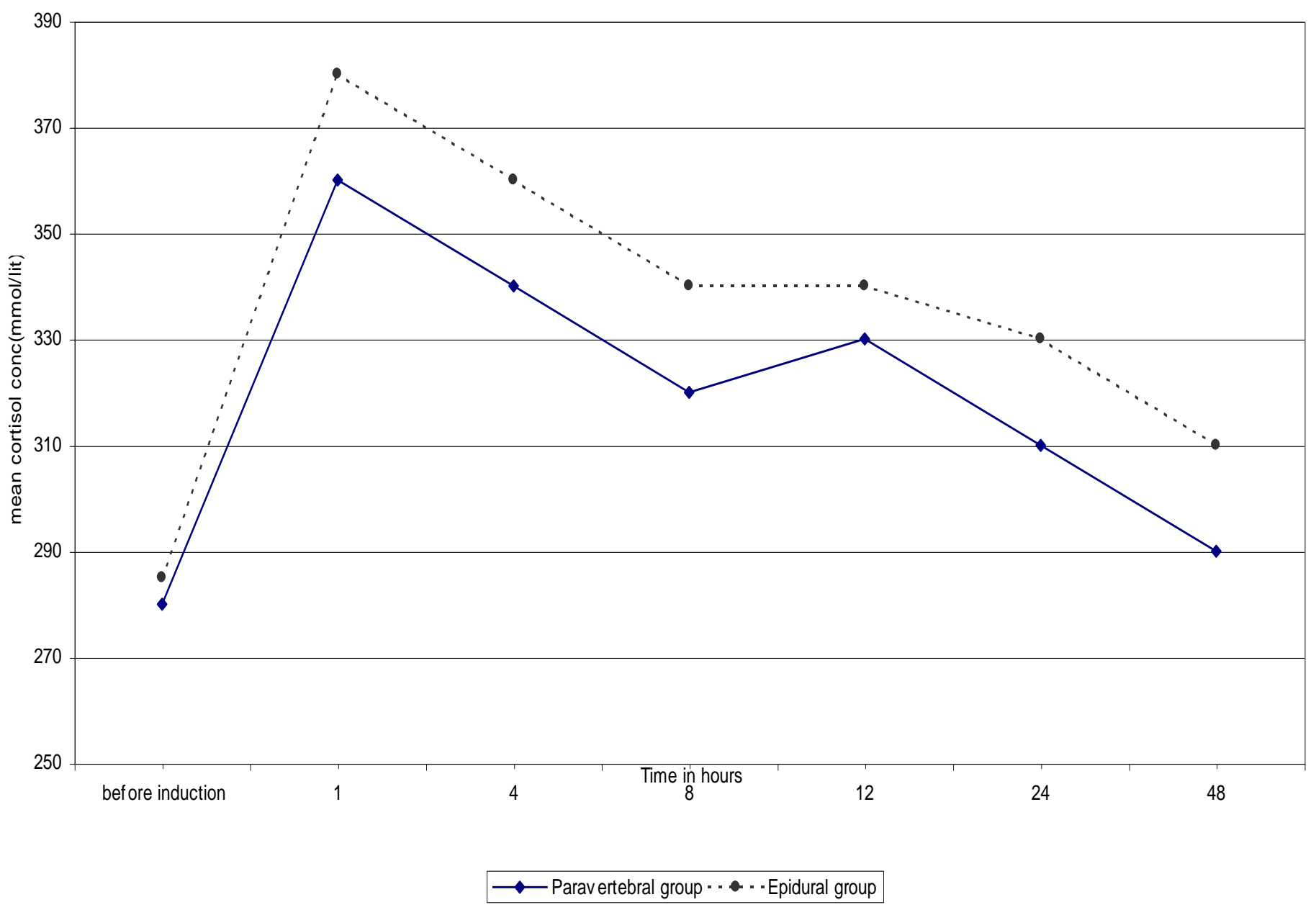


Table (8) : Blood glucose concentration (mmol/liter) (mean \pm SD) in paravertebral and epidural groups.

\begin{tabular}{|l||l|l|}
\hline Time (h) & Paravertebral group & Epidural group \\
\hline \hline Before induction & $5.1 \pm 1.1$ & $5.3 \pm 1.9$ \\
1 & $4.9 \pm 0.9$ & $5.5 \pm 1.3$ \\
4 & $5.6 \pm 1.4$ & $5.6 \pm 1.3$ \\
8 & $5.4 \pm 1.4$ & $5.5 \pm 1.6$ \\
12 & $5.5 \pm 1.3$ & $5.6 \pm 1.3$ \\
24 & $4.9 \pm 1.6$ & $5.1 \pm 1.1$ \\
48 & $5.2 \pm 1.2$ & $5.4 \pm 1.4$ \\
\hline
\end{tabular}

Table (9) : frequency of adverse effects in paravertebral and epidural groups.

\begin{tabular}{|l|l|l|}
\hline & Paravertebral group & Epidural group \\
\hline \hline Hypotension & - & 3 \\
Urine retention & - & 2 \\
Nausea & 2 & 4 \\
Vomiting & - & - \\
Numb/heavy legs & - & 2 \\
Drowsiness confusion & - & - \\
Difficulty in breathing & 3 & 5 \\
Itching & - & - \\
\hline
\end{tabular}

\section{Discussion :}

The paravertebral thoracotomy wound is exceedingly painful and contribute to postoperative pulmonary dysfunction. Analgesia sufficient to permit deep inspiration and productive coughing without respiratory depression is necessary to restore adequate spontaneous ventilation after thoracic surgery. Continuous epidural analgesia or paravertebral blockade is more likely to achieve these aims than systemic opioids (Aitkenhead et al., 2001).

In the present study both paravertebral and epidural blocks provided effective technique for post thoracotomy pain relief. Although paravertebral group showed better pain scores at rest and on coughing, the patients were able to breath spontaneously and to cough effectively in both groups. Meanwhile Perttunen and colleagues, (1995) found that both paravertebral and epidural blocks have comparable risk-benefit ratios. The auth -ors considered the consumption of PCA morphine a valid measure of the efficacy of the various anesthetic blocks.

In this study no significant difference in morphine consumption was noted between the two groups, which provide an evidence that epidural block was as effective as paravertebral block. This is in consistent with Mathews and Govenden, (1989) who reported equally post thoracotomy analgesia with both extradural or paravertebral blocks. 


\section{Paravertebral And Epidural}

Thoracotomy produces marked alteration in pulmonary function (Engberg and Wilkuland, 1988 ; Spence and Smith, 1998). One of the earliest changes is the marked reduction in effort dependent lung volumes (FVC, $\mathrm{FEV}_{1}$ and PEFR) which is an important factor in the development of pulmonary dysfunction (Meyers et al., 1975). Also Sabanathan et al., (1993) speculated that pain is the most important factor responsible for the decrease in respiratory reserve after thoracotomy and effective postoperative analgesia may improve respiratory mechanisms. In this study effort dependent lung volumes were reduced significantly four hours postoperatively in both groups. Improved pulmonary function tests were recorded thereafter throughout the study period. However paravertebral block showed an advantage on pulmonary function in the present study, Warner et al., (1996) demonstrated that epidural local anaesthetic inhibited effort related exhalation. The authors carried out this effect to bilateral partial intercostal nerve blocks as weakness in the intercostal muscles is known to be induced by epidural local anaesthetic. While the paravertebral block effects are unilateral so contralateral chest wall function is relatively unaffected (Richardson and Lönnqvist 1998). However, in this study, both techniques lead to better oxygenation in the postoperative period which was probably related to better postoperative pulmonary function because of less pain on coughing in both groups. This was evident by the decrease in the respiratory rate recorded throughout the study period in the two groups.

Sensory levels of analgesia assessed by pinprick sensation, in this study, revealed comparable extent of sensory blockade in both groups. Most patients in paravertebral group showed a unilateral blockade. This is consistent with Lönnqvist, (1992) who noted that paravertebral blockade is almost invari ably unilateral. Meanwhile Mulroy, (1996) pointed out that an epidural band of anesthesia may be obtained following paravertebral technique. Using comp uted tomography, the authors demons trated a diffusion of the local anesthetic into the vertebral canal through the intervertebral foramina (Mulroy 1996 ; Karmaker et al., 2000). This could exp lain the bilateral sensory blockade noted in the three cases of the paravertebral group.

Prevention of afferent input to the central nervous system is important for pain modulation. Profound afferent block should prevent the neurological stimulus for the initiation of the neuro endocrine stress response to surgery (Richardson et al 1998). Although there was no significant changes in blood glucose level in both paravertebral and epidural groups, a significant increase in plasma cortisol level was noted in the two groups respectively. In this study, the area under the curve in plasma cortisol level showed an evidence that the increase in plasma cortisol was significantly less in paravertebral group. This modification of neuroendocrine stress responses after thoracic surgery has been demonstrated previously in studies done by Giesecke et al., (1988). The modification of stress responses was explained by somatic nerves together with block of the sympathetic chain and the rami communicants when local anesthetic is placed alongside the vertebral column in paravertebral block rather than the anatomically distant from it in the epidural space (Richardson et al., 1998).

Both the frequency and seriousness of the complications found in this study were lower in the 
paravertebral group than those recorded with epidural blockade. Although Lönnqvist, (1998) believed that paravertebral blocks can be performed effectively and safely and it deserves to be used more widely for unilateral perioperative analgesia, the author pointed out this block should not be performed in patients with coarctation of the aorta or those undergoing aortic aneurysm repair. Also Thomas and colleagues, (1999) advised caution in performing percutaneous paravertebral block in patients who have already undergoing thoracotomy because inev itable adhesion formation tend to alter the anatomy of paravertebral gutter and increase the risk of morbidity.

We concluded that paravertebral and epidural blocks are effective for post thoracotomy pain. This study showed that paravertebral analgesia was superior in terms of analgesia, pulmonary function, neuroendocrine stress responses and side effects. As significant proportion of postoperative pain is sympathetically mediated from the pleura in thoracic surgery, the extrapleural intercorstal nerve blocks which work via the paravertebral route provide a reliable method of unilateral analgesia. This deserves to be widely considered in thoracic surgery especially in critically ill patients.

\section{References :}

1. Aitkenhead AR, Rowbotham DJ, Smith G 2001. Textbook of Anesthesia. $4^{\text {th }}$ edition Churchill Livingstone, ch. 58, p. $699-710$.

2. Cheema SPS, Ilsley D, Richardson J, et al 1995. A thermographic study of paravert ebral Analgesia Anaesthesia 50 : $118-21$.
3. Dickenson AH 1995. Spinal cord pharmacology of pain. $\mathrm{Br} \mathrm{J}$ Anaesth, $193-200$.

4. Eason M, Wyatt R 1979. Paravertebral thoracic block-a reap praisal. Anaesthesia, 34 : $638-42$.

5. Engberg G, Wilkuland L (1988). Pulmonary complications after upper abdominal and thoracic surgery : their prevention with intercostal blocks. Acta Anaesthesiol Scand, 32:1-9.

6. Giesecke K, Hamberger B, Jarnberg, et al 1988. Paravertebral block during cholecystectomy : Effects on circulatory and hormonal responses. Br J Anaesth, 61 : 652 56.

7. Karmaker MK, Kwork WK, Kew J 2000. Thoracic paravertebral block : Radiological evidence of contrala -teral spread anterior to the vertebral bodies. Br J Anaesth. 84 : $263-5$.

8. Lönnqvist PA 1992. Continuous paravertebral block in children-initial experience. Anaesthesia, 47 : 607 - 9 .

9. Matthews PJ, Govenden V 1989. Comparison of continuous paravert -ebral and extradural infusions of bupivacaine for pain relief after thoracotomy. $\mathrm{Br} \quad \mathbf{J}$ Anaesth, $62: 204-5$.

10. Meyers JR, Lembeck L, Baue $\mathrm{AE}$ 1975. Changes in functional residual capacity of the lung after operation. Arch Surg, 110 : 576 83.

11. Mulroy MF 1996. Regional anaesthesia an illustrated procedure guide $2^{\text {nd }}$ edition. Little Brown and Compant, chap 10, p. 139 - 46.

12. Pettunen K, Nilsson E, Heinonen J, et al 1995. Extradural, paravertebral and intercostal nerve 


\section{Paravertebral And Epidural}

blocks for thoracotomy pain. $\mathrm{Br} \mathrm{J}$ Anaesth, $75: 541-7$.

13. Richardson J, Sabanathan S, Eng $\mathbf{J}$ et al 1993 : continuous intercostal nerve block versus epidural morphine for post thoracotomy analgesia. Ann Thora Surg, $55: 377$ - 80 .

14. Richardson J, Lönnqvist PA 1998. Thoracic paravertebral blockade. A review. Br J Anaesth, $81: 230-8$.

15. Richardson J, Sabanathan S, Jones J, et al 1999. A prospective, randomized comparison of preope rative and continuous balanced epidural or paravertebral bupivac aine on post thoractotomy pain, pulmonary function and stress responses. Br J Anaesth, 83 (3) 387 $-92$.
16. Sabanathan S., Richardson J, Mearns AJ 1993. Management of pain in thoracic surgery. Br Resp Med, $50: 114$ - 20.

17. Spence AA, Smith G 1998. Postoperative analgesia and lung functions : A comparison of morphine with extradural block. Br J Anaesth, $81: 948-88$.

18. Thomas PW, Sanders DJ, Berrisford RG (1999). Pulmonary haemorrhage after percutaneous paravertebral block. Br J Anaesth, 83: $668-69$.

19. Warner D, Warner M, Ritman E 1996. Human chest wall function during epidural anaesthesia. Anaesthesiology, 85 : $761-3$ 
الحقن بجوار العدود الفقري والحقن خارج ألام الجافية لعلاج الألم

ا.م/ فاطمة أحمد على \& ا.م/ أميرة محمد نصار \& د د طارق السعيد

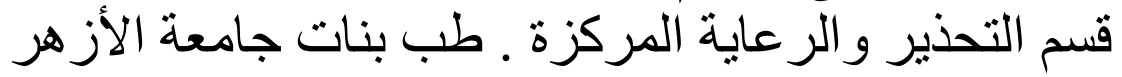

يعـانى مرضـى جر احـة الصـدر مـن آلام شديدة بـالجر ح بعد العمليـات الجر احيـة.

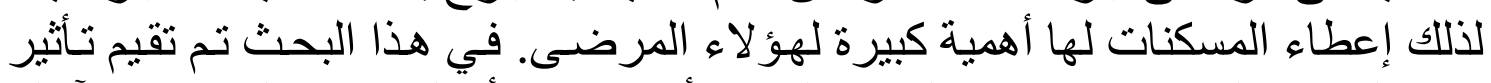

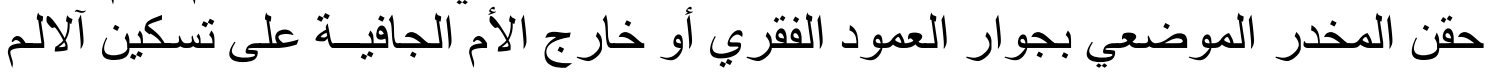

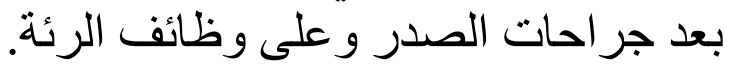

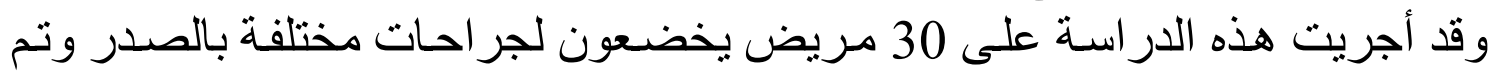

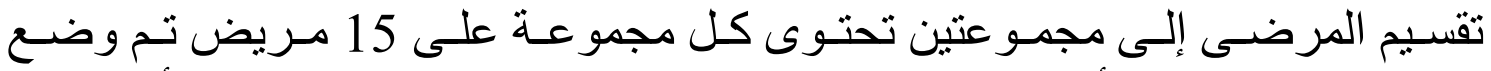

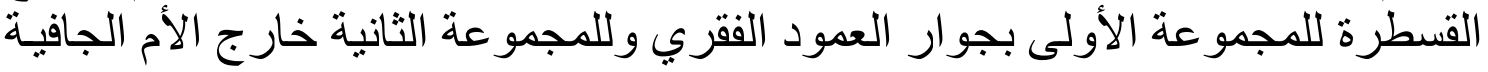

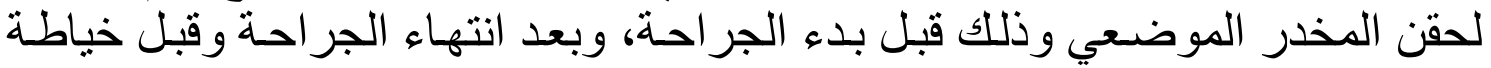

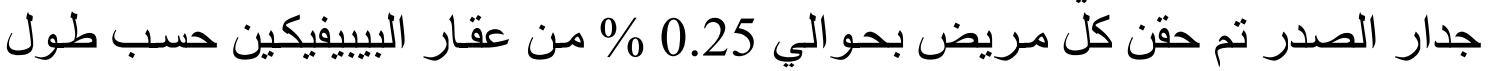

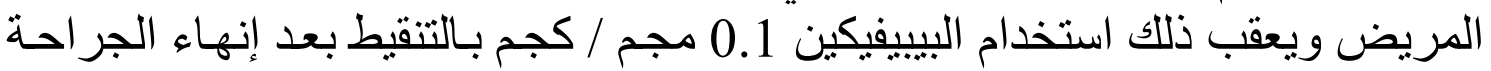

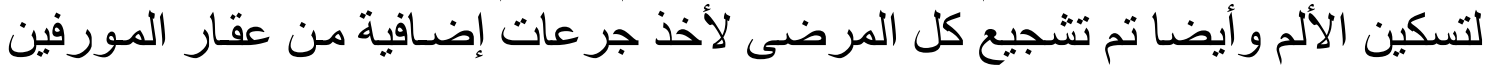

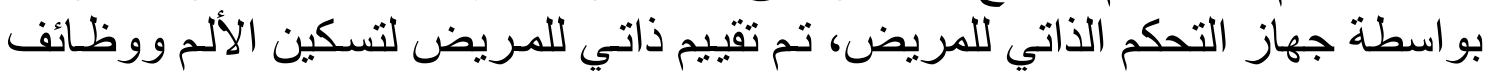

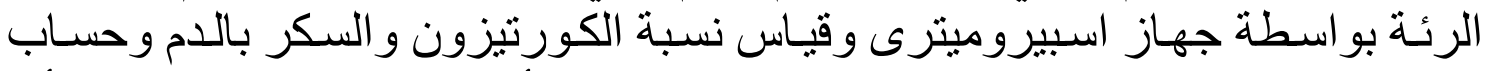

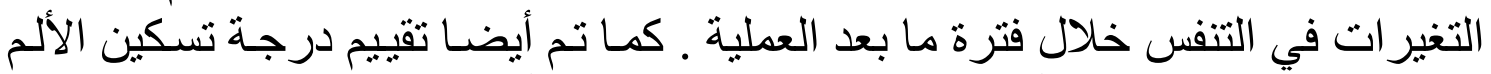

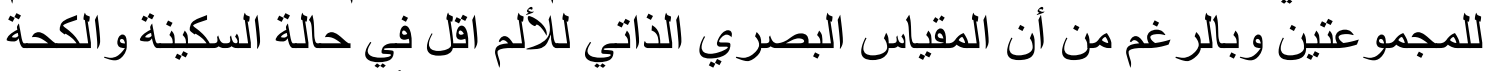

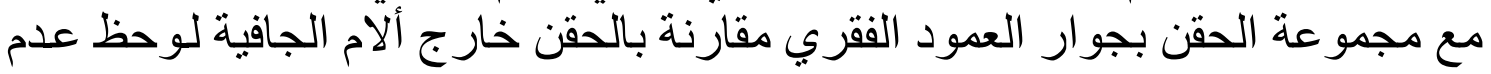

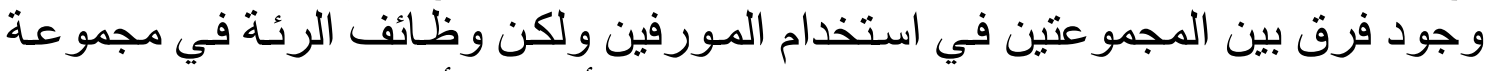

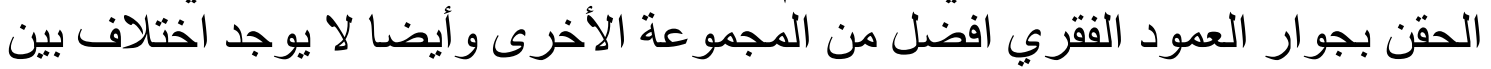

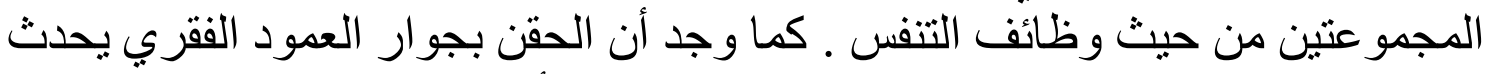

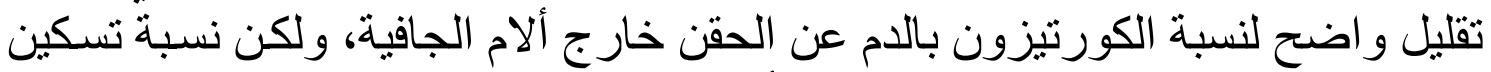

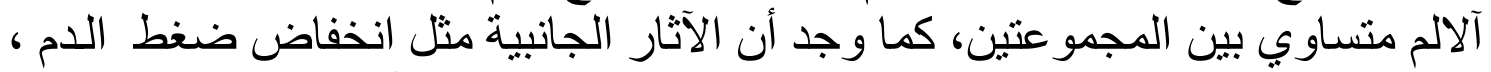

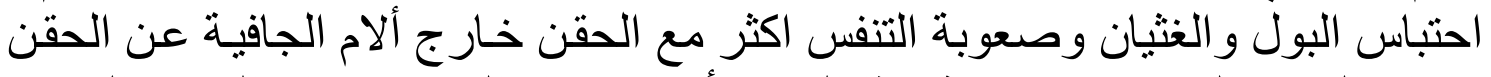

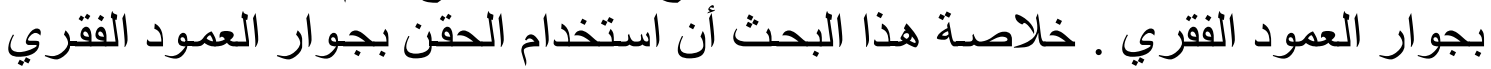

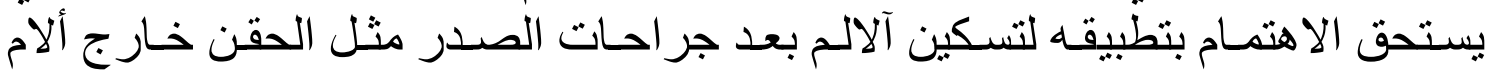
الجافية . - الجية 